\title{
Computational Study on Mössbauer Isomer Shifts of Some Organic-neptunium (IV) Complexes
}

\author{
Masashi Kaneko, ${ }^{1}$ Sunao Miyashita, ${ }^{1}$ Satoru Nakashima ${ }^{1,2, *}$
}

${ }^{1}$ Graduate School of Science, Hiroshima University, Kagamiyama, Higashi-Hiroshima, Hiroshima 739-8526, Japan

2 Natural Science Center for Basic Research and Development, Hiroshima University, Kagamiyama, Higashi-Hiroshima, Hiroshima 739-8526, Japan

* Corresponding author's e-mail address: snaka@hiroshima-u.ac.jp

RECEIVED: September 29, 2015 * REVISED: December 22, 2015 * ACCEPTED: January 13, 2016

THIS PAPER IS DEDICATED TO DR. SVETOZAR MUSIĆ ON THE OCCASION OF HIS $70^{\text {Th }}$ BIRTHDAY

\begin{abstract}
Relativistic DFT calculations are applied to some organo-neptunium (IV) complexes, $\mathrm{Cp}_{3} \mathrm{~Np}^{1 \mathrm{~V} X}\left(\mathrm{Cp}=\eta^{5}-\mathrm{C}_{5} \mathrm{H}_{5} ; \mathrm{X}=\mathrm{BH} 4, \mathrm{Cl}, \mathrm{OtBu}, \mathrm{Ph}, n \mathrm{Bu}\right)$, in order to understand their bonding properties between $\mathrm{Np}$ and the ligands. We employ scalar-relativistic ZORA Hamiltonian with all-electron basis set (SARC). The calculated electron densities at Np nucleus position in the complexes at B2PLYP / SARC theory strongly correlate to the experimental Mössbauer isomer shifts of ${ }^{237} \mathrm{~Np}$ system. The result of bond overlap population analysis indicates that the bonding strength decreases in order of $\mathrm{X}=\mathrm{BH}, \mathrm{Cl}, \mathrm{OtBu}, \mathrm{Ph}$ and $n \mathrm{Bu}$. The tendency depends on the degree of the covalent interaction between Np $5 f$-electron and $\mathrm{X}$ ligand. It is suggested that it is important to estimate the bonding contribution of $5 f$-orbital to understand the electronic state for organoactinide complexes.
\end{abstract}

Keywords: actinide chemistry, Mössbauer isomer shifts, relativistic DFT approach, bond overlap population.

\section{INTRODUCTION}

A CTINIDE chemistry includes some fundamental and applicative interests. For example, the organoactinide complexes, such as $\left[\mathrm{Cp}_{2} \mathrm{Th}^{\mathrm{IV}} \mathrm{X}_{2}\right]\left(\mathrm{Cp}=\eta^{5}-\mathrm{C}_{5} \mathrm{H}_{5} ; \mathrm{X}=\right.$ alkyl, etc.), have been investigated as a candidate for the catalyst for the hydroelementation to unsaturated carboncarbon bond. ${ }^{[1,2]}$ Moreover, the chemical separation of minor-actinides, including $\mathrm{Am}$ and $\mathrm{Cm}$, from lanthanides is an important and challenging quest, leading to the disposal of high-level radioactive waste..$^{[3,4]}$ In both fundamental and applicative cases, it is one of the most interesting tasks to understand how $5 f$-electron behaves toward the bonding state in actinide compounds.

Density functional theory (DFT) has been employed as a useful tool to describe the electronic states for actinide compounds. ${ }^{[5-7]}$ Kaltsoyannis et al. performed the relativistic DFT calculation for $\mathrm{An}^{\mathrm{III}} \mathrm{Cp}_{3}$ and $\mathrm{An}^{\mathrm{IV}} \mathrm{Cp}_{4}(\mathrm{An}=\mathrm{Th}-\mathrm{Cm})$ to discuss the bonding properties of $A n$ ions by means of various population analyses. ${ }^{[8,9]}$ We have reported that allelectron relativistic DFT results strongly correlate to the experimental ${ }^{237} \mathrm{~Np}$ Mössbauer isomer shifts, which are quantitative parameters relative to $\mathrm{Np}$ ions. ${ }^{[10]}$ We have also suggested that the bonding types of $f$-electron to a metal-ligand bond, which include bonding, non-bonding and anti-bonding, correlate to their stability. ${ }^{[11]}$

We aim to investigate the bonding state in actinide complexes to give a new insight to the bonding behavior of $5 f$-electron. The present study focuses on the bonding properties of some tris-(cyclopentadienyl) neptunium (IV) complexes, $\mathrm{Cp}_{3} \mathrm{~Np}^{\mathrm{IV} X}$. DFT study on their electronic and bonding states had never been reported, although their experimental values of ${ }^{237} \mathrm{~Np}$ Mössbauer isomer shifts are available. ${ }^{[12]}$ Here we discuss the contribution of $5 f$-electron to the bonding interaction in these complexes by relating the calculated electron density and molecular orbital (MO) population to the ${ }^{237} \mathrm{~Np}$ Mössbauer experiments. We believe that this study contributes to understanding the bonding property in $5 f$-block chemistry.

\section{COMPUTATIONAL DETAILS}

Mössbauer isomer shift $(\delta)$, which is a quantitative indicator of the bonding strength of a Mössbauer element, 
has a linear correlation with the electron density at a Mössbauer nucleus position $\left(\rho_{0}\right):^{[13]}$

$$
\delta=a\left(\rho_{0}-b\right)
$$

where $a$ and $b$ are fitting parameters. $\rho_{0}$ can be obtained by a quantum chemical calculation at all-electron level, because core electrons, such as $1 s_{1 / 2}$ and $2 p_{1 / 2}$ electrons, need to be included to get the electron density at the nucleus. The estimation of a linear correlation between the experimental $\delta$ and the calculated $\rho_{0}$ enables us to evaluate the performance of a computational method. Model compounds for this study are listed in Table 1 with the experimental Mössbauer isomer shifts reported by Karraker and Stone. ${ }^{[12,14]}$ We referred the experimental $X$-ray structures of the corresponding complexes ${ }^{[15-18]}$ and subsequently optimized all the geometries of $\mathrm{Cp}_{3} \mathrm{~Np}^{\mathrm{IV} X}$ complexes. Normal vibrational frequencies were calculated for the equilibrium structures obtained by geometry optimization. Complexes with $\mathrm{X}=\mathrm{Cl}$ and $n \mathrm{Bu}$ were created by changing a center metal to $\mathrm{Np}$ atom. Complex with $\mathrm{X}=$ $\mathrm{O} t \mathrm{Bu}$ was constructed by substituting a $t \mathrm{Bu}$ group for a $\mathrm{Ph}$ group. We considered $\mathrm{X}=\mathrm{BH}_{4}$ complex as that $\mathrm{BH}_{4}{ }^{-}$ligand works as a tridentate hydrogen donor, as indicated in the infrared spectroscopic study for $\mathrm{Cp}_{3} \mathrm{U}^{\mathrm{IV}}\left(\mathrm{BH}_{4}\right)$ complex reported by Marks and Kolb. ${ }^{[19]}$ Complex with $\mathrm{X}=\mathrm{Ph}$ was assumed as that $\mathrm{Ph}^{-}$ligand coordinates to $\mathrm{Np}^{\mathrm{IV}}$ ion as a $\eta^{1-}$ carbon donor, although the single crystal structures of their analogues have never been characterized.

All DFT calculations were performed by using ORCA ver. 3.0.0 program. ${ }^{[20]}$ Zeroth-order relativistic approximation (ZORA) ${ }^{[21]}$ was employed for all-electron Kohn-Sham Hamiltonian at scalar-relativistic level, which was constructed with model potential approximation. ${ }^{[22]}$ Although ZORA method tends to underestimate the core electron densities compared to two-component Dirac method, ${ }^{[21]}$ this underestimation might be systematic and hardly affect the comparison among Np complexes. Spinorbit coupling was neglected. Segmented all-electron relativistically contracted (SARC) basis sets optimized for ZORA Hamiltonian were assigned to $\mathrm{Np}$ element ${ }^{[23]}$ and the other atoms.[24] Geometry optimizations and standard vibrational modes calculations were carried out at ZORABP86 level of theory with SV-ZORA plus one polarization function. ZORA-BP86 with SV-ZORA reproduced the experimental geometries for $\mathrm{Eu}$ and $\mathrm{Np}$ complexes. ${ }^{[10]}$ Single-point calculations were performed at ZORA-B2PLYP level of theory with TZV-ZORA plus one polarization function. ZORA-B2PLYP with TZV-ZORA reproduced the experimental Mössbauer isomer shifts for ${ }^{151} \mathrm{Eu}$ and ${ }^{237} \mathrm{~Np} .{ }^{[10]}$ The accuracy of self-consistent-field (SCF) calculation was achieved under the same condition with our previous work. ${ }^{[10,11]}$ We set the ground state of $\mathrm{Np}$ complexes to spin quartet and obtained their electronic states by unrestricted Kohn-Sham equation. The resolution of the identity (RI) approximation, Split-RI-J[25] or RIJCOSX, ${ }^{[26]}$ was employed into all SCF calculations for pureDFT or hybrid-DFT procedure, respectively. The molecular geometries and the topologies of molecular spinor orbitals were visualized three-dimensionally by using VESTA ver. 3.3.0 program. ${ }^{[27]}$ Density of states (DOS) and overlap population analyses were carried out in order to evaluate the bonding nature between $\mathrm{Np}$ ion and ligands by Mulliken's procedure. ${ }^{[28]}$

\section{RESULTS AND DISCUSSION}

\section{Equilibrium Structures of $\mathrm{Cp}_{3} \mathrm{~Np}^{\mathrm{IV}} \mathrm{X}$}

All equilibrium structures by geometrical optimization were obtained in local minima, where all normal vibrational modes have positive frequencies. As shown in Figure 1, their structures have three $\eta^{5}$-Cp ligands, which are arranged with the approximately $C_{3 v}$ symmetry. Table 2 shows that the calculated $\mathrm{Np}-\mathrm{C}(\mathrm{Cp})$ lengths are $2.76-2.78 \AA$ for all systems. It was indicated that the coordination environments consisting of $\mathrm{Np}$ and three $\mathrm{Cp}$ ligands are almost the same for all $\mathrm{Cp}_{3} \mathrm{NpX}$ geometries. For $\mathrm{X}=\mathrm{Cl}$, OtBu

Table 1. Model compounds for calculation with experimental ${ }^{237} \mathrm{~Np}$ Mössbauer isomer shifts $\left(\delta_{\mathrm{Np}}{ }^{\mathrm{exp}}\right)$ and reference compounds.

\begin{tabular}{|c|c|c|}
\hline Model compounds & $\delta_{\mathrm{Np}}{ }^{\exp } / \mathrm{mms}^{-1}(\mathrm{a})$ & Reference compounds ${ }^{(b)}$ \\
\hline $\mathrm{Cp}{ }_{3} \mathrm{~Np}^{\mathrm{IV}}\left(\mathrm{BH}_{4}\right)$ & $14.5 \pm 4^{\text {(c) }}[$ Ref. 12] & $\mathrm{Cp}_{3} \mathrm{U}^{\mathrm{IV}}(\mathrm{HBBN})^{(\mathrm{e})}[$ Ref. 15] \\
\hline $\mathrm{Cp}_{3} \mathrm{~Np}^{\mathrm{IV}} \mathrm{Cl}$ & $14 \pm 10$ [Ref. 14] & $\mathrm{Cp}_{3} \mathrm{U}^{\prime \vee} \mathrm{Cl}$ [Ref. 16] \\
\hline $\mathrm{Cp}_{3} \mathrm{~Np}^{\mathrm{IV}}(\mathrm{O} \mathrm{B} \mathrm{Bu})$ & $8.6 \pm 3$ [Ref. 12] & $\mathrm{Cp}_{3} \mathrm{~Np}^{\mathrm{IV}}(\mathrm{OPh})$ [Ref. 17] \\
\hline $\mathrm{Cp} \mathrm{p}_{3} \mathrm{~Np} \mathrm{IV}^{\mathrm{IV}}(\mathrm{Ph})$ & $4.2 \pm 2.8^{(\mathrm{d})}[$ Ref. 12] & $\mathrm{Cp}_{3} \mathrm{U}^{\mathrm{IV}}(n \mathrm{Bu})$ [Ref. 18] \\
\hline $\mathrm{Cp}_{3} \mathrm{~Np}^{\mathrm{IV}}(n \mathrm{Bu})$ & $2.7 \pm 0.7$ [Ref. 12] & $\mathrm{Cp}_{3} \mathrm{U}^{\mathrm{IV}}(\mathrm{nBu})$ [Ref. 18] \\
\hline
\end{tabular}

\footnotetext{
(a) Relative values to $\mathrm{NpAl}_{2}$ at $4.2 \mathrm{~K}$ with experimental errors.

(b) Single crystal $\mathrm{X}$-ray structures employed in creating the starting coordinates of model compounds.

(c) Experimental value of $(\mathrm{MeCp})_{3} \mathrm{~Np}^{\mathrm{IV}}\left(\mathrm{BH}_{4}\right)$ complex.

(d) Experimental value of $\mathrm{Cp}_{3} \mathrm{~Np}^{\mathrm{IV}}\left(\mathrm{C}_{6} \mathrm{H}_{4} \mathrm{C}_{2} \mathrm{H}_{5}\right)$ complex.

(e) HBBN means 9-borabicyclo(3.3.1)nonane hydride.
} 


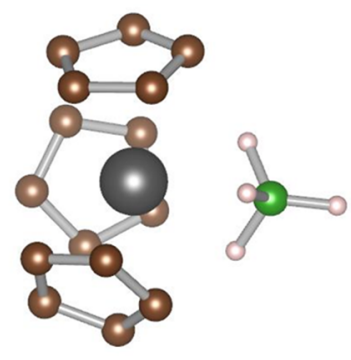

(a) $\mathrm{X}=\mathrm{BH}_{4}$

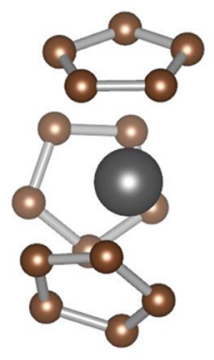

(b) $\mathrm{X}=\mathrm{Cl}$

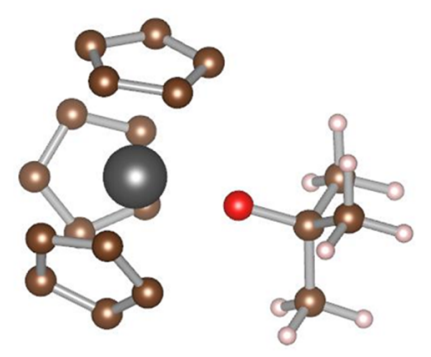

(c) $\mathrm{X}=\mathrm{O} t \mathrm{Bu}$

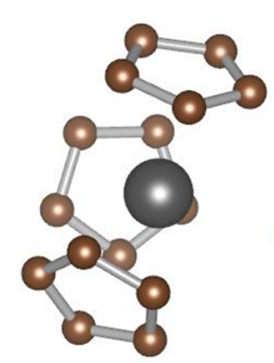

(d) $\mathrm{X}=\mathrm{Ph}$

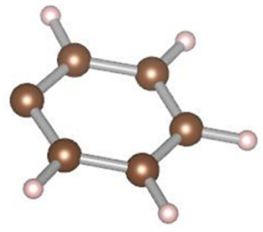$$
=\mathrm{Ph}
$$

Figure 1. Three-dimensional descriptions of optimized $\mathrm{Cp}_{3} \mathrm{NpX}$ complexes, $\mathrm{X}=\mathrm{BH}_{4}(\mathrm{a}), \mathrm{X}=\mathrm{Cl}(\mathrm{b}), \mathrm{X}=\mathrm{OtBu}(\mathrm{c}), \mathrm{X}=\mathrm{Ph}(\mathrm{d})$, and $\mathrm{X}=n \mathrm{Bu}(\mathrm{e})$, without hydrogens of $\mathrm{Cp}$ rings for clarity. Black, blue, red, brown, green and light pink spheres show $\mathrm{Np}, \mathrm{Cl}, \mathrm{O}, \mathrm{C}, \mathrm{B}$ and $\mathrm{H}$ elements, respectively.

and $n \mathrm{Bu}$ complexes, it was found that the calculated values of $\mathrm{Np}-\mathrm{C}(\mathrm{Cp})$ and $\mathrm{Np}-\mathrm{X}$ lengths are consistent with the experimental values. The obtained structure of $\mathrm{X}=\mathrm{BH}_{4}$ has three bridging hydrogens ( $\left.\mathrm{H}_{\text {bridge}}\right)$ and one terminal hydrogen $\left(\mathrm{H}_{\text {terminal }}\right)$ of $\mathrm{BH}_{4}{ }^{-}$ligand, as shown in Figure $1 \mathrm{a}$. Table 3a shows the selected IR frequencies obtained by the normal vibrational mode calculation without any scaling factors. The calculated IR frequencies of $\mathrm{C}-\mathrm{H}(\mathrm{Cp})$ wagging and $\mathrm{B}-\mathrm{H}$ stretching vibrations reproduced the corresponding experimental vibrations. The calculation for $\mathrm{X}=\mathrm{Ph}$ complex shows that $\mathrm{Ph}^{-}$ligand has $\sigma$-type coordination property (Figure $1 \mathrm{~d}$ ). The calculated IR frequencies for $X=P h$ complex are shown in Table 3b. It was confirmed by the vector analysis of normal vibration modes that the vibrational frequencies of 1200-1300 and $1400-1600 \mathrm{~cm}^{-1}$ are assigned to the vibrations attributed to $\mathrm{Ph}^{-}$ligand, being consistent with the corresponding experimental frequencies ${ }^{[29]}$ (Table $3 \mathrm{~b}$ ). Because stretching vibration frequency of aromatic $\mathrm{C}=\mathrm{C}$ bond is in this region, $\mathrm{Ph}^{-}$ligand in complex remains to have an aromaticity. These results support the above assumption that $\mathrm{Ph}^{-}$ligand has a $\eta^{1}$-coordination mode.

\section{Correlation Between $\rho_{0}{ }^{\text {calc }}$ and $\delta_{\mathrm{Np}}{ }^{\text {exp }}$}

We performed the calculation of $\rho_{0}$ at Np nucleus position for the optimized $\mathrm{Cp}_{3} \mathrm{NpX}$ structures at ZORA-B2PLYP /

Table 2. Calculated bond lengths between metal and ligands for $\mathrm{Cp}_{3} \mathrm{NpX}$ complexes and the comparison with some experimental values

\begin{tabular}{ccccccccc}
\hline \multirow{2}{*}{ Bond lengths $/ \AA$} & $\mathrm{X}=\mathrm{BH}_{4}$ & \multicolumn{2}{c}{$\mathrm{X}=\mathrm{Cl}$} & \multicolumn{2}{c}{$\mathrm{X}=\mathrm{OtBu}$} & $\mathrm{X}=\mathrm{Ph}$ & \multicolumn{2}{c}{$\mathrm{X}=n \mathrm{Bu}$} \\
\cline { 2 - 9 } & Calc. & Calc. & Exp. [Ref. 16] & Calc. & Exp. [Ref. 17] & Calc. & Calc. & Exp. [Ref. 18] \\
\hline $\mathrm{M}-\mathrm{C}(\mathrm{Cp})_{\text {ave }}$ & $2.776(12)$ & $2.757(10)$ & $2.741(38)$ & $2.777(16)$ & $2.733(16)$ & $2.765(12)$ & $2.765(9)$ & $2.739(39)$ \\
$\mathrm{M}-\mathrm{X}$ & $2.316(10)$ & 2.595 & 2.556 & 2.085 & 2.137 & 2.489 & 2.435 & 2.426 \\
\hline
\end{tabular}


Table 3. Comparison in IR frequencies $\left(\mathrm{cm}^{-1}\right)$ between calculation and experiment for complexes with $\mathrm{X}=\mathrm{BH}_{4}$ (a) and $\mathrm{X}=\mathrm{Ph}(\mathrm{b})$

\begin{tabular}{ccc} 
(a) $\mathrm{X}=\mathrm{BH}_{4}$ & & \\
\hline $\begin{array}{c}\mathrm{Cp}_{3} \mathrm{~Np}\left(\mathrm{BH}_{4}\right) \\
\text { Calc. (a) }\end{array}$ & $\begin{array}{c}\mathrm{Cp}_{3} \mathrm{U}\left(\mathrm{BH}_{4}\right) \\
\text { Exp. [Ref.19] }\end{array}$ & Assignment \\
\hline 800,828 & 797,825 & $\mathrm{C}-\mathrm{H}(\mathrm{Cp})$ in-plane wagging \\
1014 & 1020 & $\mathrm{C}-\mathrm{H}(\mathrm{Cp})$ out-of-plane wagging \\
2226,2251 & $2160,2220,2295$ & $\mathrm{~B}-\mathrm{H}_{\text {bridge }}\left(\mathrm{BH}_{4}\right)$ stretching \\
2551 & 2480 & $\mathrm{~B}-\mathrm{H}_{\text {terminal }}\left(\mathrm{BH}_{4}\right)$ stretching \\
\hline
\end{tabular}

(b) $\mathrm{X}=\mathrm{Ph}$

\begin{tabular}{|c|c|c|}
\hline $\mathrm{Cp}_{3} \mathrm{~Np}(\mathrm{Ph})$ & $\mathrm{Cp}_{3} \mathrm{U}\left(\mathrm{C}_{6} \mathrm{~F}_{5}\right)$ & \multirow{2}{*}{ Assignment } \\
\hline Calc.(a) & Exp.[Ref.29] & \\
\hline 770 & 739 & $\mathrm{C}-\mathrm{H}(\mathrm{Cp})$ in-plane wagging \\
\hline 1008 & 945 & $\mathrm{C}-\mathrm{H}(\mathrm{Cp})$ out-of-plane wagging \\
\hline 1178,1272 & 1248,1315 & $\begin{array}{c}\mathrm{C}-\mathrm{H}(\mathrm{Ph}) \text { or } \mathrm{C}-\mathrm{F}\left(\mathrm{C}_{6} \mathrm{~F}_{5}\right) \\
\text { in-plane wagging }\end{array}$ \\
\hline $1400,1443,1574$ & $1415,1540,1628$ & $\mathrm{C}-\mathrm{C}(\mathrm{Ph})$ stretching \\
\hline
\end{tabular}

TZVP(SARC) level of theory. Figure 2 shows the correlation between experimental $\delta_{\mathrm{Np}}$ and calculated $\rho_{0}$ values. It was found that calculated $\rho_{0}$ values strongly correlate to experimental $\delta_{\mathrm{Np}}$ values with negative linear relationship, in which correlation coefficient $(R)$ is $-0.968 .{ }^{237} \mathrm{~Np}$ isomer shifts can be calculated by using the fitting parameters $a$ and $b$ in Equation (1), which are obtained by the linear regression analysis between $\rho_{0}$ calc and $\delta_{\mathrm{Np}}{ }^{\text {exp }}$. The calculated $\delta_{\mathrm{Np}}$ values reproduced the experimental $\delta_{\mathrm{Np}}$ values within their experimental errors (Table 4). The negative correlation between $\rho_{0}{ }^{\text {calc }}$ and $\delta_{\mathrm{Np}}{ }^{\exp }$ is consistent with the experimental fact that $\Delta R / R$ value, where $R$ is Mössbauer nucleus radii and $\Delta R$ is defined as $\Delta R$ ( $\left.=R^{\text {excited }}-R^{\text {ground }}\right)$ of ${ }^{237} \mathrm{~Np}$ Mössbauer transition is negative, ${ }^{[30]}$ since $\Delta R / R$ is correlated to $a$ with the following equation:[13]

$$
(\Delta R / R)=a\left(5 \varepsilon_{0} E_{\gamma}\right) /\left(3 Z e^{2} c R^{2}\right)
$$

where $\varepsilon_{0}, e$ and $c$ are dielectric constant, elementary charge and the speed of light, respectively. $Z$ and $E_{\gamma}$ mean the atomic number and the $\gamma$-ray transition energy of Mössbauer nucleus, respectively. We also calculated $\Delta R / R$ value by using Equation (2), in which an approximate value of $R$ as $1.2 A^{1 / 3} \mathrm{fm}$ ( $A$ : the mass number of Mössbauer nucleus) is introduced, resulting in $-2.44 \times 10^{-4}$. This value correlates to the experimental value $\left(\Delta\left\langle r^{2}\right\rangle \mid\left\langle r^{2}\right\rangle=-3.5 \times\right.$ $\left.10^{-4}\right),{ }^{30}$ since $\left.\Delta<r^{2}\right\rangle \mid\left\langle r^{2}\right\rangle$ value is approximately double of
Table 4. Calculated $\rho_{0}$ and $\delta_{\mathrm{Np}}$ values, which were obtained by fitting parameters $a, b$ (Eq. 1), at ZORA-B2PLYP / SARC theory with experimental $\delta_{\mathrm{Np}}$ values

\begin{tabular}{|c|c|c|c|}
\hline$x$ & $\delta_{\mathrm{Np}} \mathrm{exp}^{\mathrm{ex}} \mathrm{mms}^{-1}$ & $\rho_{0}^{\text {calc }} /$ a.u. $^{-3}$ & $\delta_{\mathrm{Np}}^{\text {calc }} / \mathrm{mms}^{-1}$ \\
\hline $\mathrm{BH}_{4}$ & $14.5(40)$ & 13180638.890 & 14.63 \\
\hline $\mathrm{Cl}$ & $14(10)$ & 13180644.139 & 12.20 \\
\hline $\mathrm{OtBu}$ & $8.6(30)$ & 13180647.573 & 10.61 \\
\hline $\mathrm{Ph}$ & $4.2(28)$ & 13180662.004 & 3.94 \\
\hline$n B u$ & $2.7(7)$ & 13180664.857 & 2.62 \\
\hline \multicolumn{2}{|c|}{ Correlation efficient $(R)$} & \multicolumn{2}{|c|}{-0.968} \\
\hline \multicolumn{2}{|c|}{ a / a.u. ${ }^{3} \mathrm{mms}^{-1}$} & \multicolumn{2}{|c|}{-0.462} \\
\hline \multicolumn{2}{|r|}{ b/a.u..$^{-3}$} & \multicolumn{2}{|c|}{13180670.529} \\
\hline \multicolumn{2}{|c|}{$M A D^{(a)} / m^{-1}$} & \multicolumn{2}{|c|}{0.86} \\
\hline
\end{tabular}

$\Delta R / R$ value. However, it should be noted that this calculation includes some limitations as pointed out by Filatov and coworkers. ${ }^{[31]}$ This is because Equation (2) derived by non-relativistic treatment is employed and the finite nucleus effect is not considered for $\rho_{0}$ values obtained by the present ZORA-DFT calculation.

\section{Population Analyses for $\mathrm{Cp}_{3} \mathrm{NpX}$ Complexes}

The negative linear correlation between $\rho_{0}$ and $\delta_{\mathrm{Np}}$ values means that the core electrons, mainly including $1 s$ and $2 s$ electrons, are more shielded by the valence electrons with the increase in $\delta_{\mathrm{Np}}$, leading to smaller $\rho_{0}$. We have already reported that the valence $f$-electron density relates to the

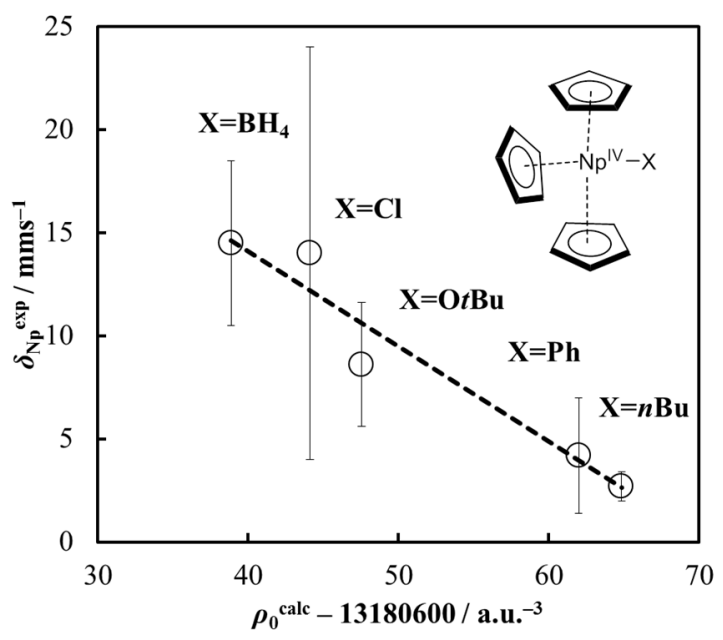

Figure 2. Plot of calculated $\rho_{0}\left(\rho_{0}^{\text {calc }}\right)$ versus experimental $\delta_{\mathrm{Np}}\left(\delta_{\mathrm{Np}}{ }^{\mathrm{exp}}\right)$ for $\mathrm{Cp}_{3} \mathrm{NpX}$ complexes at ZORA-B2PLYP / SARC theory. 
tendency in $\delta_{\mathrm{Np}}$ values. ${ }^{[10]}$ Although the correlation with $s$ orbital population and the tendency in the $\mathrm{Np}$-ligand lengths are interesting points, any correlation and tendency were not observed. In this section, we focus on the relationship between $f$-orbital population and $\delta_{\mathrm{Np}}$ values. The result of the visualization of the molecular orbitals, where the valence $f$-electron of $\mathrm{Np}$ atom distributes, shows the observation of the bond overlapping between $5 f$-orbital of $\mathrm{Np}$ and ligands. Figure 3 exhibits the topological description of the selected MOs for complexes with $\mathrm{X}=\mathrm{BH}_{4}$ and $n \mathrm{Bu}$. Complex with $\mathrm{X}=\mathrm{BH}_{4}$ has the large overlapping between $\mathrm{Np} f$-orbital and $\mathrm{BH}_{4}^{-}$ligand (Figure 3a). On the other hand, complex with $\mathrm{X}=n \mathrm{Bu}$ has the smaller overlapping compared to complex with $\mathrm{X}=\mathrm{BH}_{4}$ and

(a) $\mathrm{X}=\mathrm{BH}_{4}$ complex:

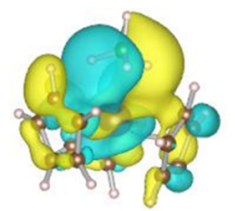

$\operatorname{HOMO}(\alpha)-11$

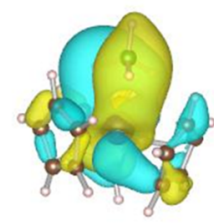

$\operatorname{HOMO}(\alpha)-8$

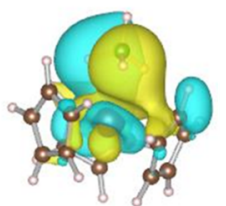

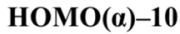

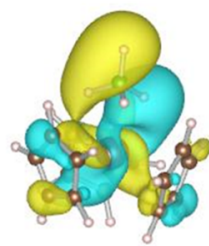

$\operatorname{HOMO}(\alpha)-7$

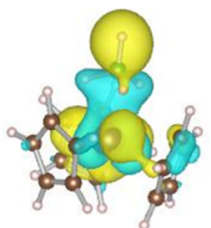

$\operatorname{HOMO}(\alpha)-9$

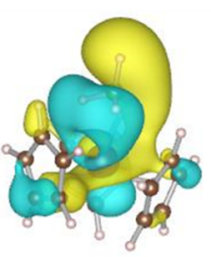

$\operatorname{HOMO}(\alpha)-6$ (b) $\mathrm{X}=n$ Bu complex:
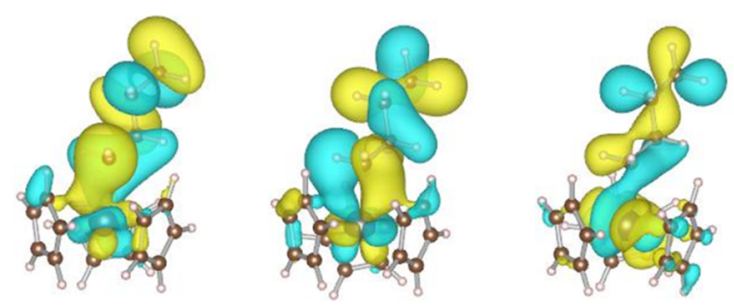

$\operatorname{HOMO}(\alpha)-13$

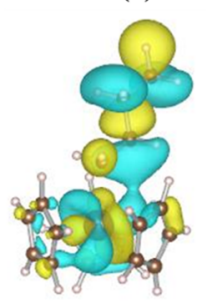

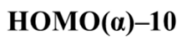

$\operatorname{HOMO}(\alpha)-12$

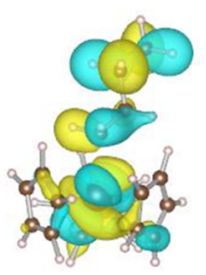

$\operatorname{HOMO}(\alpha)-9$
$\operatorname{HOMO}(\alpha)-11$

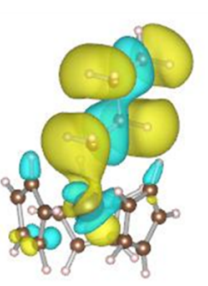

$\operatorname{HOMO}(\alpha)-8$

Figure 3. Isosurface density of selected $\mathrm{MOs}$ of complexes with $\mathrm{X}=\mathrm{BH}_{4}(\mathrm{a})$ and $\mathrm{X}=n \mathrm{Bu}(\mathrm{b})$ at $0.00005 \mathrm{e} / \mathrm{bohr}^{3}$.

also has anti-bonding overlap character, as seen in $106 \alpha$, $107 \alpha$ and $108 \alpha$ MOs (Figure 3b). It was also found that complex with $\mathrm{X}=\mathrm{Cl}$ has the same bonding nature to that with $\mathrm{X}=\mathrm{BH}_{4}$, while complexes with $\mathrm{X}=\mathrm{O}$ tBu and $\mathrm{Ph}$ have the same character to that with $X=n B u$. It might be indicated that the bonding strength between $f$-orbital of $\mathrm{Np}$ atom and ligands for complexes with $\mathrm{X}=\mathrm{BH}_{4}$ and $\mathrm{Cl}$ is stronger than those of the other complexes.

In order to understand this difference from the viewpoint of $f$-orbital bonding, we performed the bond overlap population (BOP) analysis between $\mathrm{Np}$ and $\mathrm{X}$-donor atoms in valence MOs. BOP analysis enables us to evaluate the bonding type and strength of the focusing bond overlap. The value of BOP was estimated by the following equation: 28

$$
n_{i}^{k l}=2 S^{k l} c_{i}^{k} c_{i}^{\prime}=2 \Sigma_{\mu} \Sigma_{v} S_{\mu v}{ }^{k l} c_{i}^{k \mu} c_{i}^{\prime v}
$$

where $n_{l}^{k l}$ is overlap population between $\varphi^{k}$ and $\varphi^{l}$ atomic orbitals in $i$-th $\mathrm{MO}$. $S^{k l}$ and $c_{i}$ show the overlap integral between $\varphi^{k}$ and $\varphi^{\prime}$ atomic orbitals and the MO coefficient of each $\mathrm{AO}$ in $i$-th $\mathrm{MO}$, respectively. Since atomic orbitals are described as linear combination of basis function, $n_{i}{ }^{k l}$ is evaluated by the sum of products $S_{\mu \nu}{ }^{k l}$, which is the overlap integral between $\chi_{\mu}{ }^{k}$ and $\chi_{\nu}{ }^{\prime}$ basis functions belonging to $\varphi^{k}$ and $\varphi^{\prime}$, respectively, $c_{i}^{k \mu}$ and $c_{i}^{\prime v}$, which are the MO coefficients of each basis function in $i$-th MO. Figure 4 shows the partial density of states (PDOS) of $\mathrm{Np}$ $5 f$-electron and the BOP as the solid line and the broken line, respectively, for $\mathrm{Cp}_{3} \mathrm{NpX}$ complexes. There exits about $90 \%$ of the valence three $5 f$ electrons in the orbital energy region from -12 to $-10 \mathrm{eV}$ for all complexes (Figure 4). Focused on the contribution of BOP in this region, complexes with $\mathrm{X}=\mathrm{BH}_{4}$ and $\mathrm{Cl}$ have more positive BOP contribution, that is, larger bonding contribution compared to the others. Comparing complexes among $X$ $=\mathrm{O} t \mathrm{Bu}, \mathrm{Ph}$ and $n \mathrm{Bu}$, complex with $\mathrm{X}=n \mathrm{Bu}$ has the largest anti-bonding contribution among them. The integral value of $\mathrm{BOP}$ in this region decreases in order of $\mathrm{X}=\mathrm{BH}_{4}$ (0.262), $\mathrm{Cl}$ (0.199), OtBu (0.134), $\mathrm{Ph}$ (0.039) and $n \mathrm{Bu}$ (0.031), correlating to the tendency in the decrease of $\delta_{\mathrm{Np}}$ value. This result implies that the larger covalent interaction of the $\mathrm{Np}-\mathrm{X}$ bond leads to the larger $\delta_{\mathrm{Np}}$ value, resulting in the smaller $\rho_{0}$ and vice versa. This tendency can be understood by considering the shielding effect of $f$-electron. For example, in the case of strong bonding interaction such as $\mathrm{X}=\mathrm{BH}_{4}$ or $\mathrm{Cl}$, the increase of the electron density of $f$-orbital by the strong donation of $X$ ligand leads to the large shielding to core electrons, resulting in the small $\rho_{0}$. Through the above discussion, we indicate that the bonding strength between $f$-electron of $\mathrm{Np}$ and $\mathrm{X}$ atom correlates to the experimental ${ }^{237} \mathrm{~Np}$ Mössbauer isomer shifts for $\mathrm{Cp}_{3} \mathrm{NpX}$ complexes. 

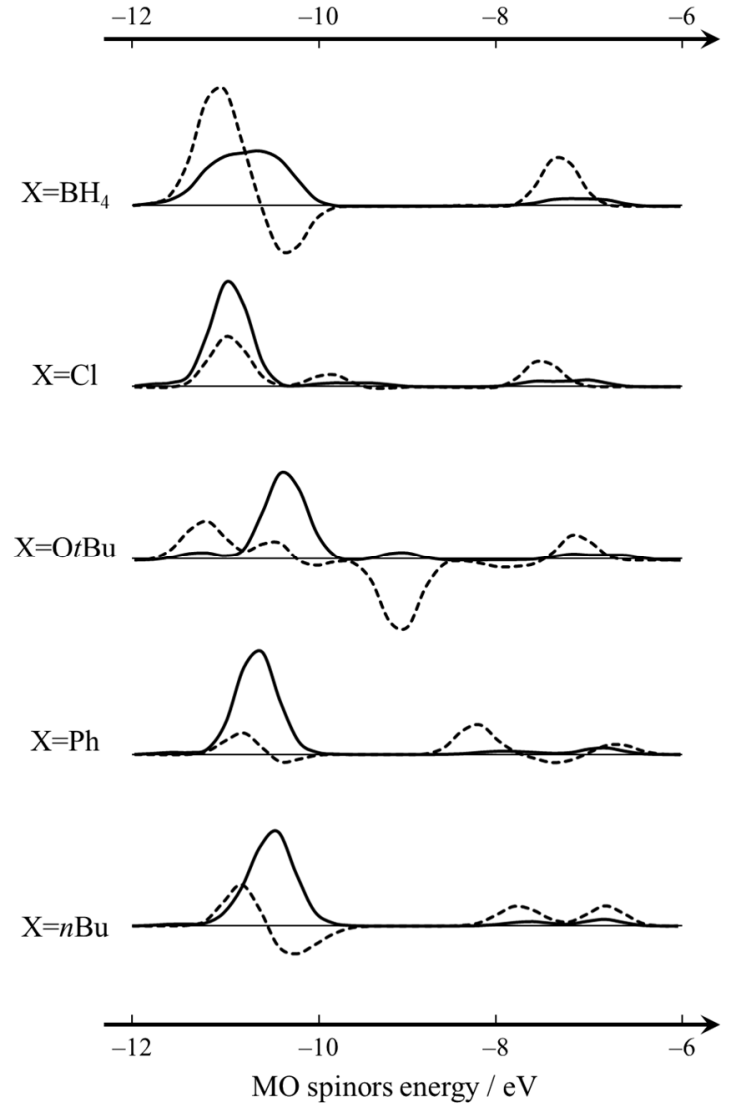

Figure 4. Partial density of states (PDOS) curve of $\mathrm{Np} 5 f$ electron (solid line) and bond overlap population (BOP) curve between $\mathrm{Np}$ and donor atoms of $\mathrm{X}$ ligand (broken line) in $\alpha$-spinor valence region. Both curves were normalized by same values and obtained by Gaussian-type line with the half-width value of $0.1 \mathrm{eV}$.

\section{CONCLUSION}

We discussed the electronic and bonding states of $\mathrm{Cp}_{3} \mathrm{NpX}$ $\left(\mathrm{X}=\mathrm{BH}_{4}, \mathrm{Cl}, \mathrm{OtBu}, \mathrm{Ph}, n \mathrm{Bu}\right.$ ) complexes by means of allelectron relativistic DFT calculation. The validity of the optimized geometries of these compounds was confirmed by comparing them with the previously published X-ray structures. The electron densities at $\mathrm{Np}$ nucleus position $\left(\rho_{0}\right)$ calculated by ZORA-B2PLYP / SARC theory strongly correlated to the experimental ${ }^{237} \mathrm{~Np}$ Mössbauer isomer shifts $\left(\delta_{\mathrm{Np}}\right)$. The calculated $\Delta R / R$ value obtained by the linear regression analysis between the calculated $\rho_{0}$ and the experimental $\delta_{\mathrm{Np}}$ values reproduced the negative sign of the experimental value. Finally, the result of the bond overlap population between $\mathrm{Np}$ atom and $\mathrm{X}$ ligand might suggest that the covalency of $\mathrm{Cp}_{3} \mathrm{NpX}$ complexes depends on the contribution of $5 f$-electron to $\mathrm{Np}-\mathrm{X}$ bond. The fundamental discussion, such as the bonding nature, for actinide compounds leads to the rigorous understanding of their stability and reactivity. Moreover, the participation or nonparticipation of $f$-electron to the covalent interaction was discussed. ${ }^{[11]}$ We believe that this study gives a new insight for the basic and applied actinide chemistries.

\section{REFERENCES}

[1] C. J. Weiss, T. J. Marks, Dalton Trans. 2010, 39, 6576.

[2] L. Castro, A. Yahia, L. Maron, ChemPhysChem 2010, $11,990$.

[3] M. J. Hudson, L. M. Harwood, D. M. Laventine, F. W. Lewis, Inorg. Chem. 2013, 52, 3414.

[4] J. Lan, W. Shi, L. Yuan, J. Li, Y. Zhao, Z. Chai, Coord. Chem. Rev. 2012, 256, 1406.

[5] N. Kaltsoyannis, Chem. Soc. Rev. 2003, 32, 9.

[6] G. Schreckenbach, G. A. Shamov, Acc. Chem. Res. 2010, 43, 19.

[7] D. Wang, W. F. van Gunsteren, Z. Chai, Chem. Soc. Rev. 2012, 41, 5836.

[8] I. Kirker, N. Kaltsoyannis, Dalton Trans. 2011, 40, 124.

[9] M. J. Tassell, N. Kaltsoyannis, Dalton Trans. 2010, 39, 6719.

[10] M. Kaneko, S. Miyashita, S. Nakashima, Dalton Trans. 2015, 44, 8080.

[11] M. Kaneko, S. Miyashita, S. Nakashima, Inorg. Chem. 2015, 54, 7103.

[12] D. G. Karraker, J. A. Stone, Inorg. Chem. 1979, 18, 2205.

[13] F. Neese, Quantum Chemistry and Mössbauer Spectroscopy, in: P. Gütlich, E. Bill, and A. X. Trautwein (Eds.), Mössbauer Spectroscopy and Transition Metal Chemistry - Fundamentals and Applications, Springer, Berlin, 2011, p. 150.

[14] D. G. Karraker, J. A. Stone, Inorg. Chem. 1972, 11, 1742.

[15] P. Zanella. F. Ossola, M. Porchia, G. Rossetto, J. Organomet. Chem. 1987, 323, 295.

[16] C. Wong, T. Yen, T. Lee, Acta Cryst., 1965, 18, 340.

[17] D. J. A. De Ridder, C. Apostolidis, J. Rebizant, B. Kanellakopulos, R. Maier, Acta Cryst. Sect. C 1996, $52,1436$.

[18] G. Perego, M. Cesari, F. Farina, G. Lugli, Acta Cryst. Sect. B 1976, 32, 3034.

[19] T. J. Marks, J. R. Kolb, J. Am. Chem. Soc. 1975, 97, 27.

[20] F. Neese, WIREs Comput. Mol. Sci. 2012, 2, 73.

[21] E. van Lenthe, E. J. Baerends, J. G. Snijders, J. Chem. Phys. 1993, 99, 4597.

[22] C. van Wüllen, J. Chem. Phys. 1998, 109, 392.

[23] D. A. Pantazis, F. Neese, J. Chem. Theory. Comput. 2011, 7, 677.

[24] D. A. Pantazis, X. Chen, C. R. Landis, F. Neese, J. Chem. Theory Comput. 2008, 4, 908. 
[25] F. Neese, J. Comput. Chem. 2003, 35, 1740.

[26] F. Neese, F. Wennmohs, A. Hansen, U. Becker, Chem. Phys. 2009, 356, 98.

[27] K. Momma, F. Izumi, J. Appl. Crystallogr. 2008, 41, 653.

[28] R. S. Mulliken, J. Chem. Phys. 1955, 23, 2338.
[29] T. J. Marks, A. S. Seyam, J. R. Kolb, J. Am. Chem. Soc. 1973, 95, 5529.

[30] B. D. Dunlap, G. M. Kalvius, S. L. Ruby, M. B. Brodsky, D. Cohen, Phys. Rev. 1968, 171, 316.

[31] M. Filatov, Coord. Chem. Rev. 2009, 5-6, 594. 